\title{
International R\&D Rivalry with Spillovers and Policy Cooperation in R\&D Subsidies and Taxes
}

\author{
PEI-CHENG LIAO
}

Department of Accounting, National Taiwan University

\begin{abstract}
We have investigated non-cooperative and jointly optimal R\&D policies in the framework of Spencer \& Brander (1983) in the presence of R\&D spillovers. When R\&D activities are strategic substitutes and the R\&D game exhibits a positive externality, the result of Spencer \& Brander (1983) reverses: the non-cooperative policy is a tax while the jointly optimal policy is a subsidy. Moreover, when R\&D activities are strategic complements, the usual result of the prisoners' dilemma in the strategic subsidy game does not hold, implying that a welfare intervention is preferable over laissez-faire. When spillovers are sufficiently large, the joint welfare increases with subsidies being higher than those under non-cooperation.
\end{abstract}

KEY WORDS: R\&D spillovers, R\&D subsidy/tax, strategic substitutes/complements, externality JEL CLASSIFICATION: F13; L13

\section{Introduction}

This paper investigates the non-cooperative and jointly optimal R\&D subsidy policies of two exporting countries in the presence of international technology spillovers. The aim of this study was to improve our understanding of the policy interactions that occur when two governments are setting their R\&D subsidy policies.

In a seminal paper, Spencer \& Brander (1983) show that an R\&D subsidy enables the domestic firm to commit to a higher R\&D investment, thereby shifting the profit of the foreign firm to the domestic firm. However, they did not consider the presence of $R \& D$ spillovers between firms, and the competing $R \& D$ activities

Correspondence Address: Pei-Cheng Liao, Department of Accounting, National Taiwan University, No. 1, Sec. 4, Roosevelt Rd., Taipei 106, Taiwan. Email: pcliao@ntu.edu.tw. 
were strategic substitutes. The justification for an R\&D subsidy is evident because it enhances the incentive of the domestic firm to invest more in R\&D, thus reducing the R\&D performed by the foreign firm and increasing the profit of the domestic firm at the expense of the foreign firm. The paper by Spencer \& Brander (1983) has received considerable theoretical attention and has inspired a growing body of work addressing other modifications. For example, Bagwell \& Staiger (1992, $1994)$ introduce uncertainty in the R\&D process over the extent of cost reduction. Leahy \& Neary (1996) focus on the timing of moves and the ability of agents to commit intertemporally. Miyagiwa \& Ohno (1997) adopt an intertemporal framework and show that an optimal R\&D policy is crucially dependent on the degree of appropriability of the new technology.

The recent rapid growth in intellectual property trade and high-technology products in world markets has led to technological spillovers between firms. Moreover, the increasing number of agreements on international R\&D cooperation and research joint ventures has led to the effect of R\&D spillovers being addressed more widely in an international context. Within a country, it is recognized that R\&D activities usually involve an externality, which thus calls for government intervention. In the presence of competition in production and technology between firms in different countries and varying degrees of international technology spillovers, it is important to analyze the policies that governments in different countries should use to optimally help their local firms, and whether those policies differ when the governments cooperate in setting them. Although there is a fairly large amount of industrial organization literature on endogenous R\&D choices and R\&D policies, very few studies have analyzed R\&D policy interactions between governments within an international framework, especially cooperation that occurs at the government level. Qiu \& Tao (1998) extend Spencer \& Brander (1983) to show that both R\&D subsidies and taxes can be optimal in the case of R\&D collaboration, ${ }^{1}$ and that an R\&D subsidy is always optimal in the case of $R \& D$ coordination. ${ }^{2}$ Although they also analyze cooperation in $R \& D$ subsidies between governments in the case of R\&D coordination, the effect of R\&D spillovers between firms is not considered. Motta (1996) adopts a four-firm, two-country model to investigate the policy game in which each government can allow or forbid R\&D cooperation between its two local firms. DeCourcy (2005) extends Motta (1996) to investigate the policy game in which each government has three choices of cooperative R\&D policies: R\&D cartel, research joint venture, or research joint venture cartel. She finds that allowing firms to cooperate in R\&D is superior to using R\&D subsidies. Kang (2006) extends Spencer \& Brander (1983) by incorporating an intellectual property rights (IPR) protection policy into his model in which the two exporting countries choose both the R\&D subsidies and IPR protection levels simultaneously. At Nash equilibrium, the government of

\footnotetext{
${ }^{1}$ This is similar to the 'noncooperative R\&D with spillovers' model in d'Aspremont \& Jacquemin (1988) and Suzumura (1992), and the 'R\&D competition' model in Kamien et al. (1992). That is, the marginal cost of one firm is decreased by its own $R \& D$, in addition to there being some spillover from the R\&D of the other firm.

${ }^{2}$ This is the same as the model of Spencer \& Brander (1983) except that each firm chooses its R\&D level to maximize a weighted sum of the profits of both firms.
} 
each country optimally adopts sufficiently weak IPR protection and subsidizes R\&D. If both governments cooperate to maximize their joint welfare, they will provide no IPR protection and continue to subsidize R\&D.

There are many real-world examples of agreements on international R\&D cooperation. China and Germany established science and technology (S\&T) cooperation relations in November 1978 by signing the ChinaGermany S\&T cooperation agreement, and this cooperation has been in steady progress since then, with a series of cooperation agreements and protocols having been signed between the corresponding sectors, national S\&T organizations, and science foundations in the two countries. To date, the bilateral cooperation covers almost all key areas of S\&T, from basic to applied research, from the traditional areas of energy, environment, agriculture, and health to the high-technology areas of aerospace, information technology, biotechnology, new materials, advanced manufacturing, and automation. ${ }^{3}$ Israel has also signed bilateral R\&D cooperation agreements with the United States, Canada, members of the European Union, India, and Singapore. The aim of these agreements is to encourage contacts between Israeli and overseas firms to facilitate joint ventures in R\&D, manufacturing, and marketing. Israel has been operating binational funds for financing cooperative industrial R\&D with the US, Canada, Singapore, and Britain. In addition, it has agreements for joint funding of R\&D projects with Austria, France, Germany, The Netherlands, Ireland, Portugal, and Spain. ${ }^{4}$

In this paper, we focus on non-cooperative and jointly optimal R\&D subsidy policies between governments under the framework of Spencer \& Brander (1983) in the presence of R\&D spillovers. Our work differs from that of Kang (2006) in two main ways. In Kang (2006), the demand is linear and the degree of R\&D spillovers (through an IPR protection policy) is endogenous, whereas we use a general demand function and assume that the degree of R\&D spillovers is exogenous. When the governments in the exporting countries cooperate, Kang (2006) shows that R\&D subsidies are positive and no IPR protection is provided (i.e. the spillover effect is completely perfect). Our results are more general because we analyze the R\&D subsidy policy for varying degrees of spillovers, and our model is suitable for the cases when the extent of $\mathrm{R} \& \mathrm{D}$ spillovers is not solely determined by IPR protection policy, and when the IPR protection level is not solely controlled by a country itself. 5

This paper shows that when spillovers are low (high), the R\&D game exhibits a negative (positive) externality, so the jointly optimal policy is to tax (subsidize) R\&D. When R\&D activities are strategic substitutes and the R\&D game exhibits a positive externality, the result in Spencer \& Brander (1983) reverses: the noncooperative policy is a tax while the jointly optimal policy is a subsidy. Moreover, when R\&D activities are strategic complements, the usual result of the prisoners'

\footnotetext{
${ }^{3}$ http://www.most.gov.cn/eng/

${ }^{4}$ http://www.mfa.gov.il/mfa

${ }^{5}$ For example, in the Uruguay Round of GATT (the General Agreement on Tariffs and Trade), an agreement on the trade-related aspects of IPRs (TRIPs) was passed despite strong resistance from developing countries. Most of the terms of the TRIPs Agreement require that all member countries adopt a minimum IPR protection level. Since developed countries already have tight IPR protection, the main of effect of this agreement is to constrain developing countries.
} 
dilemma in the strategic subsidy game does not hold, implying that a welfare intervention is preferable over laissez-faire. When R\&D activities are strategic complements and the R\&D game exhibits a positive externality, the jointly optimal R\&D subsidy is greater than the non-cooperative R\&D subsidy, implying that the total welfare will be increased further if the governments provide higher R\&D subsidies for the firms in their countries. However, when R\&D activities are strategic complements and the R\&D game exhibits a negative externality, the total welfare will be increased further if the governments impose higher R\&D taxes on the firms in their countries.

The next section presents the basic three-stage model and analyzes the noncooperative Nash equilibrium in R\&D subsidy/tax policy, while the third section analyzes the jointly optimal R\&D subsidy/tax policy. The fourth section examines the case of asymmetric spillovers, and the fifth section provides some concluding remarks.

\section{The Model}

We consider a one-product, two-firm, three-country model as used by Spencer \& Brander (1983). Two of the countries, which are numbered 1 and 2, each have a firm that produces a homogeneous product to be exported to the third country, $M$. Demand in country $M$ is given by an inverse demand function, $p=p(Q)$, where $p$ is the market price. We assume that $p($.$) is decreasing and is twice continuously$ differentiable, with $p^{\prime \prime}(Q) Q+p^{\prime}(Q)<0$. The output of firm $i$ (the one in country $i)$ is denoted by $q_{i}, i=1,2$, and $Q=q_{1}+q_{2}$ in equilibrium. Initially, firm $i$ has a constant marginal cost $c_{i}$, which is independent of the production level. Each firm is able to lower its marginal cost through R\&D investment $x_{i}$. Following d'Aspremont \& Jacquemin (1988) and most of the literature, we assume that the $\mathrm{R} \& \mathrm{D}$ production function is linear. The $\mathrm{R} \& \mathrm{D}$ investment is subject to diminishing returns, as captured by the quadratic form of the R\&D cost, $\gamma x_{i}^{2} / 2, \gamma>0$. The R\&D of firm $i$ not only leads to a reduction in its own marginal cost, but also spills over to firm $j, i, j=1,2$, and $i \neq j$. For the time being, we assume that the degree of $\mathrm{R} \& \mathrm{D}$ spillovers between firms is identical. We define $\beta \in[0,1]$ as the degree of R\&D spillovers, which represents the proportion of the cost reduction of firm $i$ that enters additively and costlessly into the marginal cost reduction of firm $j$. Thus, through its own R\&D and the spillovers of the R\&D of firm $j$, the marginal cost of firm $i$ becomes $M C_{i}=c_{i}-x_{i}-\beta x_{j}$.

We consider the following three-stage, one-shot non-cooperative game. In the first stage, the governments in countries 1 and 2 simultaneously and noncooperatively announce that they are to subsidize/tax R\&D by paying/imposing a given percentage (denoted $s_{1}$ and $s_{2}$, respectively) of the R\&D expenditures. Thus, the R\&D cost of firm $i$ becomes $\gamma x_{i}^{2}\left(1-s_{i}\right) / 2,0 \leq\left|s_{i}\right|<1 .^{6}$ In the second stage, the two firms choose their respective R\&D levels, $x_{1}$ and $x_{2}$, simultaneously

\footnotetext{
${ }^{6}$ Alternatively, country $i$ may provide a subsidy/tax $s_{i}$ for the per-unit level of R\&D investment. The R\&D cost of firm $i$ then becomes $\gamma x_{i}^{2} / 2-s_{i} x_{i}$. The analysis is qualitatively similar to that presented here, and the results also hold for this form of subsidy.
} 
and non-cooperatively. In the third stage, the two firms engage in a Cournot competition. The game is solved by backward induction. To simplify the analysis, we concentrate on symmetric solutions. ${ }^{7}$

In the third stage, the maximization problem for firm $i$ is given by

$$
\max _{q_{i}} \pi_{i}=\left[p(Q)-c_{i}+x_{i}+\beta x_{j}\right] q_{i}-\frac{1}{2} \gamma x_{i}^{2}\left(1-s_{i}\right), i, j=1,2 \text {, and } i \neq j
$$

and the first-order condition is given by

$$
\frac{\partial \pi_{i}}{\partial q_{i}}=p^{\prime} q_{i}+p-c_{i}+x_{i}+\beta x_{j}=0, i, j=1,2 \text {, and } i \neq j
$$

We define $a_{i i} \equiv \partial^{2} \pi_{i} / \partial q_{i}^{2}$ and $a_{i j} \equiv \partial^{2} \pi_{i} / \partial q_{i} \partial q_{j}, i, j=1,2$, and $i \neq j$. $a_{i i}=$ $p^{\prime \prime} q_{i}+2 p^{\prime}<0$ by the second-order condition, and $a_{i j}=p^{\prime \prime} q_{i}+p^{\prime}<0$ because of strategic substitution of outputs. Then the stability condition, $\Delta_{1} \equiv a_{11} a_{22}-$ $a_{12} a_{21}=p^{\prime} p^{\prime \prime} Q+3\left(p^{\prime}\right)^{2}>0$, is satisfied. The two first-order conditions in equation (1) can be solved simultaneously to obtain the equilibrium outputs $q_{1}^{*}\left(x_{1}, x_{2}\right)$ and $q_{2}^{*}\left(x_{1}, x_{2}\right)$. The comparative statics results show that

$$
\begin{aligned}
\frac{\partial q_{i}^{*}}{\partial x_{i}} & =\frac{\beta a_{i j}-a_{j j}}{\Delta_{1}}=\frac{p^{\prime \prime}\left(\beta q_{i}^{*}-q_{j}^{*}\right)+p^{\prime}(\beta-2)}{\Delta_{1}}>0, \\
\frac{\partial q_{j}^{*}}{\partial x_{i}} & =\frac{a_{j i}-\beta a_{i i}}{\Delta_{1}}=\frac{p^{\prime \prime}\left(q_{j}^{*}-\beta q_{i}^{*}\right)+p^{\prime}(1-2 \beta)}{\Delta_{1}}
\end{aligned}
$$

Thus, the R\&D performed by firm $i$ increases its own output $q_{i}^{*}$ and the total output $Q^{*}$. However, the effect of this on $q_{j}^{*}$ depends on the magnitude of $\beta$. We define $\tilde{\beta}=\left(p^{\prime \prime} q_{j}^{*}+p^{\prime}\right) /\left(p^{\prime \prime} q_{i}^{*}+2 p^{\prime}\right)$. When $\beta>(<) \tilde{\beta}, \partial q_{j}^{*} / \partial x_{i}>(<) 0$, meaning that an increase in $x_{i}$ leads to higher (lower) $q_{j}^{*}$.

In the second stage, firm $i$ chooses the R\&D level that will maximize its profit, and the first-order condition is given by

$$
\frac{\partial \pi_{i}^{*}}{\partial x_{i}}=q_{i}^{*}\left[1+p^{\prime}\left(\frac{\partial q_{j}^{*}}{\partial x_{i}}\right)\right]-\gamma x_{i}\left(1-s_{i}\right)=0, \quad i, j=1,2, \quad \text { and } \quad i \neq j
$$

We define $b_{i i} \equiv \partial^{2} \pi_{i}^{*} / \partial x_{i}^{2}$ and $b_{i j} \equiv \partial^{2} \pi_{i}^{*} / \partial x_{i} \partial x_{j}, i, j=1,2$, and $i \neq j$. The second-order conditions, $b_{11}<0$ and $b_{22}<0$, and the stability condition $\Delta_{2} \equiv$ $b_{11} b_{22}-b_{12} b_{21}>0$ are assumed. ${ }^{8}$ Solving the two first-order conditions in equation (2) simultaneously yields the Nash equilibrium R\&D levels $x_{1}^{*}\left(s_{1}, s_{2}\right)$

\footnotetext{
${ }^{7}$ We analyze the case of asymmetric firms with different degrees of spillovers in the fourth section. ${ }^{8}$ For a linear demand and symmetric case, the second-order condition is $9 b \gamma\left(1-s_{i}\right)-2(2-\beta)^{2}>$ 0 and the stability condition requires $\left|2(2-\beta)(2 \beta-1) /\left[9 b \gamma\left(1-s_{i}\right)-2(2-\beta)^{2}\right]\right|<1$. For a general demand function, the second-order and stability conditions are satisfied if $b \gamma$ is sufficiently large.
} 
and $x_{2}^{*}\left(s_{1}, s_{2}\right)$. Totally differentiating equation (2) with respect to $s_{i}$ yields the following comparative statics results:

$$
\frac{\partial x_{i}^{*}}{\partial s_{i}}=-\frac{\gamma b_{j j} x_{i}^{*}}{\Delta_{2}}>0 \text { and } \frac{\partial x_{j}^{*}}{\partial s_{i}}=\frac{\gamma b_{j i} x_{i}^{*}}{\Delta_{2}}
$$

With symmetry, $q_{i}^{*}=q_{j}^{*}=q^{*}=Q^{*} / 2$ and $\partial q_{i}^{*} / \partial x_{j}=\partial q_{j}^{*} / \partial x_{i}$, and we have

$$
\begin{aligned}
b_{j i} \equiv & \frac{\partial^{2} \pi_{j}^{*}}{\partial x_{j} \partial x_{i}}=\left(\frac{\partial q_{j}^{*}}{\partial x_{i}}\right)\left[1+p^{\prime}\left(\frac{\partial q_{i}^{*}}{\partial x_{j}}\right)\right] \\
& +q_{j}^{*}\left[p^{\prime \prime}\left(\frac{\partial q_{i}^{*}}{\partial x_{i}}+\frac{\partial q_{j}^{*}}{\partial x_{i}}\right)\left(\frac{\partial q_{i}^{*}}{\partial x_{j}}\right)+p^{\prime}\left(\frac{\partial^{2} q_{i}^{*}}{\partial x_{j} \partial x_{i}}\right)\right] \\
= & \left(\frac{\partial q_{j}^{*}}{\partial x_{i}}\right)\left[1+p^{\prime}\left(\frac{\partial q_{i}^{*}}{\partial x_{j}}\right)+p^{\prime \prime} q_{j}^{*}\left(\frac{\partial q_{i}^{*}}{\partial x_{i}}+\frac{\partial q_{j}^{*}}{\partial x_{i}}\right)\right]+p^{\prime} q_{j}^{*}\left(\frac{\partial^{2} q_{i}^{*}}{\partial x_{j} \partial x_{i}}\right) \\
= & \left(\frac{a_{j i}-\beta a_{i i}}{\Delta_{1}}\right)\left[1+\left(\frac{a_{i j}-\beta a_{j j}}{p^{\prime \prime} Q^{*}+3 p^{\prime}}\right)+p^{\prime \prime} q_{j}^{*}\left(\frac{-1-\beta}{p^{\prime \prime} Q^{*}+3 p^{\prime}}\right)\right] \\
& +p^{\prime} q_{j}^{*}\left(\frac{\partial^{2} q_{i}^{*}}{\partial x_{j} \partial x_{i}}\right) \\
= & {\left.\left[\frac{(1-\beta)\left(p^{\prime \prime} q^{*}+2 p^{\prime}\right)-p^{\prime}}{p^{\prime}\left(p^{\prime \prime} Q^{*}+3 p^{\prime}\right)}\right] \frac{(1-\beta)\left(p^{\prime \prime} Q^{*}+2 p^{\prime}\right)+2 p^{\prime}}{p^{\prime \prime} Q^{*}+3 p^{\prime}}\right] } \\
& -\left[\frac{p^{\prime} q^{*}(1+\beta)^{2}\left(p^{\prime \prime \prime} q^{*}+2 p^{\prime \prime}\right)}{\left(p^{\prime \prime} Q^{*}+3 p^{\prime}\right)^{3}}\right]
\end{aligned}
$$

The sign of $b_{j i}$ depends on the magnitude of $\beta$. It can be shown that if $p^{\prime \prime \prime}$ is negligible, $b_{j i}<(>) 0$ when $\beta=0(1)$, and $\partial b_{j i} / \partial \beta>0 .{ }^{9}$ We define $\beta_{s}$ as the critical value that makes $b_{j i}=0 .{ }^{10}$ When $\beta<\beta_{s}, b_{j i}<0$, meaning that $x_{1}$ and $x_{2}$ are strategic substitutes, and an increase in $s_{i}$ increases $x_{i}^{*}$ but decreases $x_{j}^{*}$. When $\beta>\beta_{s}, b_{j i}>0$, meaning that $x_{1}$ and $x_{2}$ are strategic complements, and an increase in $s_{i}$ increases both $x_{i}^{*}$ and $x_{j}^{*}$.

The strategic nature of $x_{1}$ and $x_{2}$ depends on the two countervailing effects of spillover and rivalry. Suppose that $x_{1}$ is increased by one unit. This will decrease $M C_{1}$ by one, and thus firm 1 will increase its output by $-1 /\left(p^{\prime \prime} q_{1}^{*}+2 p^{\prime}\right)$ so that its marginal revenue equals its marginal cost. Then the marginal revenue of firm 2 will be decreased by $\tilde{\beta},{ }^{11}$ and the marginal cost of firm 2 will be decreased

\footnotetext{
${ }^{9}$ See Appendix A for details.

${ }^{10}$ If $p^{\prime \prime \prime}$ is negligible, it can be seen that when $p^{\prime \prime}>(<) 0, \partial^{2} q_{i}^{*} / \partial x_{j} \partial x_{i}>(<) 0$, so $\left.b_{j i}\right|_{\beta=\tilde{\beta}}<(>) 0$, implying that $\tilde{\beta}<(>) \beta_{s}$.

${ }^{11}$ The marginal revenue of firm 2 is $M R_{2}=p^{\prime} q_{2}^{*}+p$, and $\partial M R_{2} / \partial q_{1}=p^{\prime \prime} q_{2}^{*}+p^{\prime}<0$. Thus, when the output of firm 1 is increased by $-1 /\left(p^{\prime \prime} q_{1}^{*}+2 p^{\prime}\right)$, the marginal revenue of firm 2 will be decreased by $\left(p^{\prime \prime} q_{2}^{*}+p^{\prime}\right) /\left(p^{\prime \prime} q_{1}^{*}+2 p^{\prime}\right)$, which is defined as $\tilde{\beta}$.
} 
by $\beta$ due to the unit increase in $x_{1}$. If $\beta>\tilde{\beta}$, the marginal revenue of firm 2 is greater than its marginal cost, so firm 2 will increase $x_{2}$ in order to increase its output (the positive spillover effect). On the other hand, due to symmetry, an increase in $x_{2}$ will increase $q_{1}^{*}$ (because $\partial q_{1}^{*} / \partial x_{2}>0$ when $\beta>\tilde{\beta}$ ), leading to a lower price. Thus, there is a countervailing incentive for firm 2 to decrease $x_{2}$ (the negative rivalry effect). If $\beta$ is sufficiently large (i.e. $\beta>\beta_{s}>\tilde{\beta}$ when $p^{\prime \prime}>0$ or $\beta>\tilde{\beta}>\beta_{s}$ when $\left.p^{\prime \prime}<0\right)$, the positive spillover effect exceeds the negative rivalry effect, so $x_{2}$ increases as $x_{1}$ increases. Similarly, if $\beta$ is sufficiently small (i.e. $\beta<\tilde{\beta}<\beta_{s}$ when $p^{\prime \prime}>0$ or $\beta<\beta_{s}<\tilde{\beta}$ when $p^{\prime \prime}<0$ ), the negative spillover effect exceeds the positive rivalry effect, so $x_{2}$ decreases as $x_{1}$ increases. But there are two cases for intermediate values of $\beta$ : (1) $\tilde{\beta}<\beta<\beta_{s}$ when $p^{\prime \prime}>0$, and (2) $\beta_{s}<\beta<\tilde{\beta}$ when $p^{\prime \prime}<0$. In case 1 , the positive spillover effect is exceeded by the negative rivalry effect, ${ }^{12}$ so $x_{2}$ decreases as $x_{1}$ increases. Conversely, in case 2 , the negative spillover effect is exceeded by the positive rivalry effect, so $x_{2}$ increases with $x_{1}$. Therefore, when $\beta<(>) \beta_{s}, x_{1}$ and $x_{2}$ are strategic substitutes (complements).

In the first stage, the government of country $i$ chooses the R\&D subsidy so as to maximize its welfare, which is defined as the profit of firm $i$ minus the subsidy payments:

$$
\begin{aligned}
W_{i}= & \pi_{i}^{*}-\frac{1}{2} \gamma x_{i}^{* 2} s_{i}=\left[p\left(Q^{*}\right)-c_{i}+x_{i}^{*}+\beta x_{j}^{*}\right] q_{i}^{*} \\
& -\frac{1}{2} \gamma x_{i}^{* 2}, \quad i, j=1,2, \quad \text { and } \quad i \neq j
\end{aligned}
$$

The first-order condition for maximization is given by ${ }^{13}$

$$
\begin{aligned}
\frac{\partial W_{i}}{\partial s_{i}} & =\frac{\partial \pi_{i}^{*}}{\partial s_{i}}-\frac{1}{2} \gamma x_{i}^{* 2}-\gamma x_{i}^{*} s_{i} \frac{\partial x_{i}^{*}}{\partial s_{i}} \\
& =\left(\frac{\partial \pi_{i}^{*}}{\partial x_{j}}+\frac{\partial \pi_{i}^{*}}{\partial q_{j}} \frac{\partial q_{j}^{*}}{\partial x_{j}}\right) \frac{\partial x_{j}^{*}}{\partial s_{i}}+\frac{1}{2} \gamma x_{i}^{* 2}-\frac{1}{2} \gamma x_{i}^{* 2}-\gamma x_{i}^{*} s_{i} \frac{\partial x_{i}^{*}}{\partial s_{i}} \\
& =q_{i}^{*}\left(\beta+p^{\prime} \frac{\partial q_{j}^{*}}{\partial x_{j}}\right) \frac{\partial x_{j}^{*}}{\partial s_{i}}-\gamma x_{i}^{*} s_{i} \frac{\partial x_{i}^{*}}{\partial s_{i}} \\
& =0
\end{aligned}
$$

\footnotetext{
${ }^{12}$ When $p^{\prime \prime}>0$ and $\tilde{\beta}<\beta<\beta_{s}, \partial^{2} q_{1}^{*} / \partial x_{2} \partial x_{1}>0$ and $\partial q_{1}^{*} / \partial x_{2}>0$, meaning that $\partial q_{1}^{*} / \partial x_{2}$ increases with $x_{1}$. This increases the disincentive of firm 2 to invest in R\&D, with the increasing negative rivalry effect exceeding the positive spillover effect.

${ }^{13}$ To ensure the existence of the equilibrium solution, we assume that the second-order and stability conditions are satisfied in the region close to the equilibrium point. Equation (4) indicates that when $s_{i}$ is zero, a small increase (decrease) in this parameter will increase the welfare if $[\beta+$ $\left.p^{\prime}\left(\partial q_{j}^{*} / \partial x_{j}\right)\right]\left(\partial x_{j}^{*} / \partial s_{i}\right)>(<) 0$. However, a subsidy (tax) that is too high will decrease the welfare. Thus, we conclude that there is a subsidy $(\operatorname{tax})$ that will maximize the welfare, and the equilibrium solution exists.
} 
where

$$
\begin{aligned}
\beta+p^{\prime} \frac{\partial q_{j}^{*}}{\partial x_{j}} & =\beta+\frac{p^{\prime \prime}\left(\beta q_{j}^{*}-q_{i}^{*}\right)+p^{\prime}(\beta-2)}{p^{\prime \prime} Q^{*}+3 p^{\prime}} \\
& =\frac{p^{\prime \prime}\left[2 \beta q_{j}^{*}-(1-\beta) q_{i}^{*}\right]+2 p^{\prime}(2 \beta-1)}{p^{\prime \prime} Q^{*}+3 p^{\prime}}
\end{aligned}
$$

From equation (4) we have

$$
s_{i}^{*}=\frac{q_{i}^{*}\left[\beta+p^{\prime}\left(\partial q_{j}^{*} / \partial x_{j}\right)\right]\left(\partial x_{j}^{*} / \partial s_{i}\right)}{\gamma x_{i}^{*}\left(\partial x_{i}^{*} / \partial s_{i}\right)}
$$

Thus, $s_{i}^{*}>(<) 0$ if $\beta+p^{\prime}\left(\partial q_{j}^{*} / \partial x_{j}\right)$ and $\partial x_{j}^{*} / \partial s_{i}$ have the same (opposite) signs. The sign of $\beta+p^{\prime}\left(\partial q_{j}^{*} / \partial x_{j}\right)$ is equivalent to that of $\mathrm{d} \pi_{i}^{*} / \mathrm{d} x_{j}$, which is the total effect of the R\&D performed by one firm on the profit of the other firm, and equation (5) indicates that it depends on the magnitude of $\beta$. We define $\beta_{e}$ as the critical value that makes $\beta+p^{\prime}\left(\partial q_{j}^{*} / \partial x_{j}\right)=0$, and

$$
\beta_{e}=\frac{p^{\prime \prime} q_{i}^{*}+2 p^{\prime}}{2 p^{\prime \prime} q_{j}^{*}+p^{\prime \prime} q_{i}^{*}+4 p^{\prime}}
$$

If $\beta<\beta_{e}$, then $\beta+p^{\prime}\left(\partial q_{j}^{*} / \partial x_{j}\right)<0$; that is, $\mathrm{d} \pi_{i}^{*} / \mathrm{d} x_{j}<0$. Thus, the R\&D game exhibits a negative externality. If $\beta>\beta_{e}, \mathrm{~d} \pi_{i}^{*} / \mathrm{d} x_{j}>0$, and the R\&D game exhibits a positive externality.

The sign of $\partial x_{j}^{*} / \partial s_{i}$ is equivalent to that of $b_{j i}$. When $\beta<(>) \beta_{s}, b_{j i}<(>) 0$, so $\partial x_{j}^{*} / \partial s_{i}<(>) 0$. The ranking of the two critical values, $\beta_{e}$ and $\beta_{s}$, is indeterminate, since it depends on the curvature of the demand function. We have the following lemma.

Lemma 1 If the demand function is concave and $p^{\prime \prime \prime} \geq 0$ then $\beta_{e}<\beta_{s}$; that is, strategic complementarity of R\&D activities guarantees a positive externality of the R\&D game. If the demand function is linear, $\beta_{e}=\beta_{s}=0.5$.

Proof. For the proof see Appendix B.

We have the following proposition.

Proposition 1 When the R\&D spillover effect is sufficiently small or sufficiently large (i.e. $\beta \in\left[0, \min \left(\beta_{e}, \beta_{s}\right)\right)$ or $\left.\beta \in\left(\max \left(\beta_{e}, \beta_{s}\right), 1\right]\right)$, the governments should subsidize RひD. For intermediate RむD spillover effects (i.e. $\beta \in$ $\left.\left(\min \left(\beta_{e}, \beta_{s}\right), \max \left(\beta_{e}, \beta_{s}\right)\right)\right)$, the governments should tax $\mathrm{R} \sigma \mathrm{D}$. When $\beta=\beta_{e}$ or $\beta=\beta_{s}$, the governments should adopt a laissez-faire policy. 
Although Qiu \& Tao (1998) have already showed that it is possible for either R\&D subsidies or taxes to be optimal, ${ }^{14}$ Proposition 1 clearly indicates that the governments should tax R\&D when the degree of spillovers is moderate (between the two critical values) and that they should not intervene when the degree of spillovers equals either critical value. When $\beta$ is sufficiently small (i.e. less than $\left.\min \left(\beta_{e}, \beta_{s}\right)\right)$, an R\&D subsidy is optimal for the reason given by Spencer \& Bran$\operatorname{der}(1983)$. However, when $\beta$ is sufficiently large (i.e. greater than $\max \left(\beta_{e}, \beta_{s}\right)$ ), an R\&D subsidy is optimal for a different reason from that given by Spencer \& Brander (1983): due to strategic complementarity and a positive externality, a domestic $R \& D$ subsidy increases the foreign $R \& D$ investment, which in turn increases the profit of the domestic firm. There are two cases when $\beta$ is between the two critical values: (1) if $\beta_{s}<\beta<\beta_{e}$, a domestic $\mathrm{R} \& \mathrm{D}$ subsidy increases the foreign $\mathrm{R} \& \mathrm{D}$ investment (due to strategic complementarity), which in turn decreases the profit of the domestic firm (due to a negative externality); and (2) if $\beta_{e}<\beta<\beta_{s}$, a domestic R\&D subsidy decreases the foreign R\&D investment (due to strategic substitution), which in turn decreases the profit of the domestic firm (due to a positive externality). In either case, the profit-shifting effect of a domestic $\mathrm{R} \& \mathrm{D}$ subsidy is negative, so an $\mathrm{R} \& \mathrm{D}$ tax is optimal. When $\beta=\beta_{s}$ or $\beta=\beta_{e}$, either a domestic R\&D subsidy has no effect on the foreign R\&D investment, or the foreign $R \& D$ investment does not affect the profit of the domestic firm. Therefore, the profit-shifting effect is zero, and laissez-faire is optimal.

To illustrate the general result of Proposition 1, we consider the following three demand functions in closed forms.

(1) Linear demand with $p=a-b Q$. We know that $\beta_{e}=\beta_{s}=0.5$ from Lemma 1. Thus, the governments should subsidize R\&D for any value of $\beta$ except $\beta=0.5$, and adopt a laissez-faire policy when $\beta=0.5$.

(2) Concave demand with $p=a-b Q^{2}$. In Appendix $\mathrm{C}$ we show that $\beta_{e}=5 / 11$ and $\beta_{s}=0.5312$. This confirms Lemma 1 that $\beta_{e}<\beta_{s}$ when $p^{\prime \prime}<0$ and $p^{\prime \prime \prime} \geq$ 0 . Thus, when $0 \leq \beta<5 / 11$ or $0.5312<\beta \leq 1$, the governments should subsidize $\mathrm{R} \& \mathrm{D}$; when $5 / 11<\beta<0.5312$, they should tax $\mathrm{R} \& \mathrm{D}$; and when $\beta=5 / 11$ or $\beta=0.5312$, the optimal policy is laissez-faire.

(3) Convex demand with $p=a-b \ln Q$. In Appendix D we show that $\beta_{e}=0.6$ and $\beta_{s}=0.4776$. Thus, when $0 \leq \beta<0.4776$ or $0.6<\beta \leq 1$, the governments should subsidize $\mathrm{R} \& \mathrm{D}$; when $0.4776<\beta<0.6$, they should tax R\&D; and when $\beta=0.4776$ or $\beta=0.6$, the optimal policy is laissez-faire.

\section{Jointly Optimal Policy: Subsidy or Tax?}

Spencer \& Brander (1983) show that the jointly optimal policy for the two exporting countries is for their governments to tax R\&D. In this section, we examine the robustness of their result in the presence of R\&D spillovers.

\footnotetext{
${ }^{14}$ Proposition 1 of Qiu \& Tao (1998) states that in the case of international R\&D collaboration, (i) when $\lambda_{R}$ is small enough, governments subsidize R\&D investments; and (ii) when $\lambda_{R}$ is large enough, governments may or may not subsidize R\&D investments.
} 
Now suppose that in the first stage, countries 1 and 2 choose $s_{1}$ and $s_{2}$ simultaneously and cooperatively so as to maximize their total welfare. The first-order condition is given by:

$$
\begin{aligned}
\frac{\partial\left(W_{i}+W_{j}\right)}{\partial s_{i}}= & q_{i}^{*}\left(\beta+p^{\prime} \frac{\partial q_{j}^{*}}{\partial x_{j}}\right) \frac{\partial x_{j}^{*}}{\partial s_{i}}-\gamma x_{i}^{*} s_{i} \frac{\partial x_{i}^{*}}{\partial s_{i}} \\
& +q_{j}^{*}\left(\beta+p^{\prime} \frac{\partial q_{i}^{*}}{\partial x_{i}}\right) \frac{\partial x_{i}^{*}}{\partial s_{i}}-\gamma x_{j}^{*} s_{j} \frac{\partial x_{j}^{*}}{\partial s_{i}} \\
= & {\left[q_{j}^{*}\left(\beta+p^{\prime} \frac{\partial q_{i}^{*}}{\partial x_{i}}\right)-\gamma x_{i}^{*} s_{i}\right]\left(\frac{\partial x_{i}^{*}}{\partial s_{i}}\right) } \\
& +\left[q_{i}^{*}\left(\beta+p^{\prime} \frac{\partial q_{j}^{*}}{\partial x_{j}}\right)-\gamma x_{j}^{*} s_{j}\right]\left(\frac{\partial x_{j}^{*}}{\partial s_{i}}\right) \\
= & {\left[q_{j}^{*}\left(\beta+p^{\prime} \frac{\partial q_{i}^{*}}{\partial x_{i}}\right)-\gamma x_{i}^{*} s_{i}\right]\left(\frac{\partial x_{i}^{*}}{\partial s_{i}}+\frac{\partial x_{j}^{*}}{\partial s_{i}}\right) \text { (with symmetry) } } \\
= & 0
\end{aligned}
$$

We denote the jointly optimal R\&D subsidy rates as $\tilde{s}_{i}, i=1,2$. Since $\left(\partial x_{i}^{*} / \partial s_{i}\right)+$ $\left(\partial x_{j}^{*} / \partial s_{i}\right)=\gamma x_{i}^{*}\left(b_{j i}-b_{j j}\right) / \Delta_{2}>0, \tilde{s}_{i}$ and $\beta+p^{\prime}\left(\partial q_{i}^{*} / \partial x_{i}\right)$ have the same sign. Thus, when $\beta<(>) \beta_{e}, \tilde{s}_{i}<(>) 0$, and when $\beta=\beta_{e}, \tilde{s}_{i}=0$. This leads to the following proposition.

Proposition 2 When the R\&D game exhibits a negative externality (i.e. $0 \leq$ $\beta<\beta_{e}$ ), the jointly optimal policy is to tax R\&D. When the R\&D game exhibits a positive externality (i.e. $\beta_{e}<\beta \leq 1$ ), the jointly optimal policy is to subsidize R\&D. When $\beta=\beta_{e}$, the jointly optimal policy is laissez-faire.

To compare $\tilde{s}_{i}$ with $s_{i}^{*}$, evaluating $\partial\left(W_{i}+W_{j}\right) / \partial s_{i}$ at $s_{i}=s_{i}^{*}$ and $s_{j}=s_{j}^{*}$ yields

$$
\begin{aligned}
\left.\frac{\partial\left(W_{i}+W_{j}\right)}{\partial s_{i}}\right|_{s_{i}=s_{i}^{*}, s_{j}=s_{j}^{*}}= & \frac{q_{j}^{*}\left[\beta+p^{\prime}\left(\partial q_{i}^{*} / \partial x_{i}\right)\right]}{\left(\partial x_{j}^{*} / \partial s_{j}\right)} \\
& \times\left[\left(\frac{\partial x_{i}^{*}}{\partial s_{i}}\right)\left(\frac{\partial x_{j}^{*}}{\partial s_{j}}\right)-\left(\frac{\partial x_{i}^{*}}{\partial s_{j}}\right)\left(\frac{\partial x_{j}^{*}}{\partial s_{i}}\right)\right]
\end{aligned}
$$

Since $\partial x_{j}^{*} / \partial s_{j}>0$ and $\left[\left(\partial x_{i}^{*} / \partial s_{i}\right)\left(\partial x_{j}^{*} / \partial s_{j}\right)-\left(\partial x_{i}^{*} / \partial s_{j}\right)\left(\partial x_{j}^{*} / \partial s_{i}\right)\right]=\gamma^{2} x_{1}^{*} x_{2}^{*} /$ $\Delta_{2}>0$, equation (9) and $\beta+p^{\prime}\left(\partial q_{i}^{*} / \partial x_{i}\right)$ have the same sign. Thus, when $\beta<\beta_{e}$, $\partial\left(W_{i}+W_{j}\right) / \partial s_{i}<0$ at $s_{i}=s_{i}^{*}$ and $s_{j}=s_{j}^{*}$, implying $\tilde{s}_{i}<s_{i}^{*}$; when $\beta>\beta_{e}$, $\tilde{s}_{i}>s_{i}^{*}$; and when $\beta=\beta_{e}, \tilde{s}_{i}=s_{i}^{*}$. Combining this with the results of Propositions 1 and 2 yields the following proposition. 
Proposition 3 When the R\&D spillover effect is sufficiently small (i.e. $\beta \in$ $\left[0, \min \left(\beta_{e}, \beta_{s}\right)\right), \tilde{s}_{i}<0<s_{i}^{*}$. When the R\&D spillover effect is sufficiently large (i.e. $\left.\beta \in\left(\max \left(\beta_{e}, \beta_{s}\right), 1\right]\right), 0<s_{i}^{*}<\tilde{s}_{i}$. For intermediate R\&D spillover effects, $s_{i}^{*} \leq 0<\tilde{s}_{i}$ if $\beta_{e}<\beta \leq \beta_{s}$ and $\tilde{s}_{i}<s_{i}^{*} \leq 0$ if $\beta_{s} \leq \beta<\beta_{e}$, where the equalities hold when $\beta=\beta_{s}$. When $\beta=\beta_{e}, \tilde{s}_{i}=s_{i}^{*}=0$.

Proposition 3 includes some interesting results. When R\&D activities are strategic substitutes (i.e. when $0 \leq \beta<\beta_{s}$ ), $s_{i}^{*}$ and $\tilde{s}_{i}$ have opposite signs. Therefore, both countries are better off under a laissez-faire equilibrium than under a Nash equilibrium, which is the well-known result of the prisoners' dilemma in the strategic subsidy game. Moreover, when $\beta \in\left[0, \min \left(\beta_{e}, \beta_{s}\right)\right), \tilde{s}_{i}<0<s_{i}^{*}$, and the result of Spencer \& Brander (1983) is still applicable in the presence of a low spillover effect. But if $\beta_{e}<\beta<\beta_{s}, s_{i}^{*}<0<\tilde{s}_{i}$, implying a reversal of the result of Spencer \& Brander (1983).

On the other hand, when R\&D activities are strategic complements (i.e. when $\left.\beta_{s}<\beta \leq 1\right), s_{i}^{*}$ and $\tilde{s}_{i}$ have the same sign, and both countries are better off when their governments intervene than under a laissez-faire equilibrium. Thus, when the competing variables are strategic complements, the usual character of the prisoners' dilemma does not exist in the strategic subsidy game. Moreover, when $\beta \in\left(\max \left(\beta_{e}, \beta_{s}\right), 1\right], 0<s_{i}^{*}<\tilde{s}_{i}$, implying that the total welfare will be increased further if the governments provide higher $\mathrm{R} \& \mathrm{D}$ subsidies for the firms in their countries. But if $\beta_{s}<\beta<\beta_{e}, \tilde{s}_{i}<s_{i}^{*}<0$, implying that the total welfare will be increased further if the governments impose higher R\&D taxes on these firms.

\section{Asymmetric Spillovers}

The model has presumed so far that the two firms are identical, with symmetric R\&D spillovers. Now we investigate the robustness of the general results if this symmetry assumption is relaxed. The marginal cost of firm $i$ is $M C_{i}=c_{i}-x_{i}-$ $\beta_{j} x_{j}$, where $\beta_{j} \in[0,1]$ denotes the leakage from the $\mathrm{R} \& \mathrm{D}$ of firm $j, i, j=1,2$, and $i \neq j$. To simplify the analysis and provide more insights into the asymmetric case, we assume that the demand is linear and $c_{1}=c_{2}$. It is easy to show that $\beta_{i}=0.5$ is the critical value for determining the strategic nature of $\mathrm{R} \& \mathrm{D}$ activities and the sign of externality. That is, if $\beta_{i}>(<) 0.5$, then $\partial x_{j}^{*} / \partial s_{i}>(<) 0$ and $\beta_{i}+$ $p^{\prime}\left(\partial q_{i}^{*} / \partial x_{i}\right)>(<) 0$. With asymmetric spillovers, the non-cooperative subsidy in equation (6) becomes

$$
s_{i}^{*}=\frac{q_{i}^{*}\left[\beta_{j}+p^{\prime}\left(\partial q_{j}^{*} / \partial x_{j}\right)\right]\left(\partial x_{j}^{*} / \partial s_{i}\right)}{\gamma x_{i}^{*}\left(\partial x_{i}^{*} / \partial s_{i}\right)}
$$

The sign of $s_{i}^{*}$ depends on the signs of $\beta_{j}+p^{\prime}\left(\partial q_{j}^{*} / \partial x_{j}\right)$ and $\partial x_{j}^{*} / \partial s_{i}$, which in turn depend on the values of $\beta_{j}$ and $\beta_{i}$, respectively. Table 1 lists the non-cooperative subsidy policies for various values of $\beta_{1}$ and $\beta_{2}$. The governments should subsidize $\mathrm{R} \& \mathrm{D}$ if both $\beta_{1}$ and $\beta_{2}$ are less than or greater than 0.5 , they should tax R\&D if one of these variables is less than 0.5 and the other is greater than 0.5 , and they should adopt a laissez-faire policy if either one is equal to 0.5 . 
Table 1. The non-cooperative subsidy policy

\begin{tabular}{lccc}
\hline & $0 \leq \beta_{1}<0.5$ & $\beta_{1}=0.5$ & $0.5<\beta_{1} \leq 1$ \\
\hline $0.5<\beta_{2} \leq 1$ & $s_{1}^{*}<0, s_{2}^{*}<0$ & $s_{1}^{*}=0, s_{2}^{*}=0$ & $s_{1}^{*}>0, s_{2}^{*}>0$ \\
$\beta_{2}=0.5$ & $s_{1}^{*}=0, s_{2}^{*}=0$ & $s_{1}^{*}=0, s_{2}^{*}=0$ & $s_{1}^{*}=0, s_{2}^{*}=0$ \\
$0 \leq \beta_{2}<0.5$ & $s_{1}^{*}>0, s_{2}^{*}>0$ & $s_{1}^{*}=0, s_{2}^{*}=0$ & $s_{1}^{*}<0, s_{2}^{*}<0$ \\
\hline
\end{tabular}

Now we investigate the jointly optimal policy in the presence of asymmetric spillovers. Condition (8) becomes

$$
\begin{aligned}
\frac{\partial\left(W_{i}+W_{j}\right)}{\partial s_{i}}= & q_{i}^{*}\left(\beta_{j}+p^{\prime} \frac{\partial q_{j}^{*}}{\partial x_{j}}\right) \frac{\partial x_{j}^{*}}{\partial s_{i}}-\gamma x_{i}^{*} s_{i} \frac{\partial x_{i}^{*}}{\partial s_{i}} \\
& +q_{j}^{*}\left(\beta_{i}+p^{\prime} \frac{\partial q_{i}^{*}}{\partial x_{i}}\right) \frac{\partial x_{i}^{*}}{\partial s_{i}}-\gamma x_{j}^{*} s_{j} \frac{\partial x_{j}^{*}}{\partial s_{i}} \\
= & {\left[q_{j}^{*}\left(\beta_{i}+p^{\prime} \frac{\partial q_{i}^{*}}{\partial x_{i}}\right)-\gamma x_{i}^{*} s_{i}\right]\left(\frac{\partial x_{i}^{*}}{\partial s_{i}}\right) } \\
& +\left[q_{i}^{*}\left(\beta_{j}+p^{\prime} \frac{\partial q_{j}^{*}}{\partial x_{j}}\right)-\gamma x_{j}^{*} s_{j}\right]\left(\frac{\partial x_{j}^{*}}{\partial s_{i}}\right) \\
= & 0
\end{aligned}
$$

Evaluating $\partial\left(W_{i}+W_{j}\right) / \partial s_{i}$ at $s_{i}=s_{j}=0$ yields

$$
\left.\frac{\partial\left(W_{i}+W_{j}\right)}{\partial s_{i}}\right|_{s_{i}=s_{j}=0}=q_{j}^{*}\left(\beta_{i}+p^{\prime} \frac{\partial q_{i}^{*}}{\partial x_{i}}\right)\left(\frac{\partial x_{i}^{*}}{\partial s_{i}}\right)+q_{i}^{*}\left(\beta_{j}+p^{\prime} \frac{\partial q_{j}^{*}}{\partial x_{j}}\right)\left(\frac{\partial x_{j}^{*}}{\partial s_{i}}\right)
$$

When $\beta_{i}>0.5$ and $\beta_{j} \geq 0.5, \partial\left(W_{i}+W_{j}\right) /\left.\partial s_{i}\right|_{s_{i}=s_{j}=0}>0$ because the first term in equation (10) is positive and the second term is non-negative. When $\beta_{i}>0.5$ and $\beta_{j}<0.5, \partial\left(W_{i}+W_{j}\right) /\left.\partial s_{i}\right|_{s_{i}=s_{j}=0}>0 .{ }^{15}$ When $\beta_{i}=0.5, \partial\left(W_{i}+\right.$ $\left.W_{j}\right) /\left.\partial s_{i}\right|_{s_{i}=s_{j}=0}=0$ because both the first and second terms in equation (10) are zero. When $\beta_{i}<0.5$, and $\beta_{j} \geq 0.5$, the first term is negative and the second term is non-positive, so $\partial\left(W_{i}+W_{j}\right) /\left.\partial s_{i}\right|_{s_{i}=s_{j}=0}<0$. When $\beta_{j} \leq \beta_{i}<0.5, \partial\left(W_{i}+\right.$ $\left.W_{j}\right) /\left.\partial s_{i}\right|_{s_{i}=s_{j}=0}<0$, but when $\beta_{i}<\beta_{j}<0.5$, the sign of $\partial\left(W_{i}+W_{j}\right) /\left.\partial s_{i}\right|_{s_{i}=s_{j}=0}$ is ambiguous. ${ }^{16}$ Since the analysis is symmetric relative to country $j$, we know that when $\beta_{i}<0.5$ and $\beta_{j}<0.5$ there is at least one country whose jointly optimal policy is an R\&D tax. Table 2 lists the jointly optimal subsidy policies for various values of $\beta_{1}$ and $\beta_{2}$.

\footnotetext{
${ }^{15}$ See Appendix E.

${ }^{16}$ See Appendix E.
} 
Table 2. The jointly optimal subsidy policy

\begin{tabular}{lccc}
\hline & $0 \leq \beta_{1}<0.5$ & $\beta_{1}=0.5$ & $0.5<\beta_{1} \leq 1$ \\
\hline $0.5<\beta_{2} \leq 1$ & $\tilde{s}_{1}<0, \tilde{s}_{2}>0$ & $\tilde{s}_{1}=0, \tilde{s}_{2}>0$ & $\tilde{s}_{1}>0, \tilde{s}_{2}>0$ \\
$\beta_{2}=0.5$ & $\tilde{s}_{1}<0, \tilde{s}_{2}=0$ & $\tilde{s}_{1}=0, \tilde{s}_{2}=0$ & $\tilde{s}_{1}>0, \tilde{s}_{2}=0$ \\
& at least one & & \\
$0 \leq \beta_{2}<0.5$ & $\tilde{s}_{i}<0$ & $\tilde{s}_{1}=0, \tilde{s}_{2}<0$ & $\tilde{s}_{1}>0, \tilde{s}_{2}<0$ \\
\hline
\end{tabular}

Table 3. A comparison of $s_{i}^{*}$ and $\tilde{s}_{i}$

\begin{tabular}{lccc}
\hline & $0 \leq \beta_{1}<0.5$ & $\beta_{1}=0.5$ & $0.5<\beta_{1} \leq 1$ \\
\hline $0.5<\beta_{2} \leq 1$ & $\tilde{s}_{1}<s_{1}^{*}<0, s_{2}^{*}<0<\tilde{s}_{2}$ & $\tilde{s}_{1}=s_{1}^{*}=0,0=s_{2}^{*}<\tilde{s}_{2}$ & $0<s_{1}^{*}<\tilde{s}_{1}, 0<s_{2}^{*}<\tilde{s}_{2}$ \\
$\beta_{2}=0.5$ & $\tilde{s}_{1}<s_{1}^{*}=0, \tilde{s}_{2}=s_{2}^{*}=0$ & $\tilde{s}_{1}=s_{1}^{*}=0, \tilde{s}_{2}=s_{2}^{*}=0$ & $0=s_{1}^{*}<\tilde{s}_{1}, \tilde{s}_{2}=s_{2}^{*}=0$ \\
$0 \leq \beta_{2}<0.5$ & $\tilde{s}_{1}<s_{1}^{*}, \tilde{s}_{2}<s_{2}^{*}$ & $\tilde{s}_{1}=s_{1}^{*}=0, \tilde{s}_{2}<s_{2}^{*}=0$ & $s_{1}^{*}<0<\tilde{s}_{1}, \tilde{s}_{2}<s_{2}^{*}<0$ \\
\hline
\end{tabular}

To compare $\tilde{s}_{i}$ with $s_{i}^{*}$, evaluating $\partial\left(W_{i}+W_{j}\right) / \partial s_{i}$ at $s_{i}=s_{i}^{*}$ and $s_{j}=s_{j}^{*}$ yields

$$
\begin{aligned}
\left.\frac{\partial\left(W_{i}+W_{j}\right)}{\partial s_{i}}\right|_{s_{i}=s_{i}^{*}, s_{j}=s_{j}^{*}} & =\frac{q_{j}^{*}\left[\beta_{i}+p^{\prime}\left(\partial q_{i}^{*} / \partial x_{i}\right)\right]}{\left(\partial x_{j}^{*} / \partial s_{j}\right)} \\
& \times\left[\left(\frac{\partial x_{i}^{*}}{\partial s_{i}}\right)\left(\frac{\partial x_{j}^{*}}{\partial s_{j}}\right)-\left(\frac{\partial x_{i}^{*}}{\partial s_{j}}\right)\left(\frac{\partial x_{j}^{*}}{\partial s_{i}}\right)\right]
\end{aligned}
$$

which has the same sign as $\beta_{i}+p^{\prime}\left(\partial q_{i}^{*} / \partial x_{i}\right)$. Thus, $\tilde{s}_{i}>(<) s_{i}^{*}$ if $\beta_{i}>(<) 0.5$, and $\tilde{s}_{i}=s_{i}^{*}$ if $\beta_{i}=0.5$. Combining this with Tables 1 and 2 yields Table 3 , which compares $s_{i}^{*}$ and $\tilde{s}_{i}$ for various values of $\beta_{1}$ and $\beta_{2}$. Thus, we have the following proposition.

Proposition 4 Suppose that the demand function is linear and that R\&D spillovers differ between firms:

(i) If $0.5<\beta_{1} \leq 1$ and $0.5<\beta_{2} \leq 1,0<s_{i}^{*}<\tilde{s}_{i}, i=1,2$.

(ii) If $\beta_{1}=\beta_{2}=0.5, \tilde{s}_{i}=s_{i}^{*}=0, i=1,2$.

(iii) If $0 \leq \beta_{1}=\beta_{2}<0.5, \tilde{s}_{i}<0<s_{i}^{*}, i=1,2$.

(iv) If $0 \leq \beta_{j}<\beta_{i}<0.5, \tilde{s}_{i}<0<s_{i}^{*}, 0<s_{j}^{*}$, and $\tilde{s}_{j}<s_{j}^{*}, i, j=1,2$ and $i \neq j$.

(v) If $0 \leq \beta_{i}<0.5$ and $0.5<\beta_{j} \leq 1, \tilde{s}_{i}<s_{i}^{*}<0, s_{j}^{*}<0<\tilde{s}_{j}, i, j=1,2$ and $i \neq j$.

(vi) If $\beta_{i}=0.5$ and $0 \leq \beta_{j}<0.5, \quad \tilde{s}_{i}=s_{i}^{*}=0, \tilde{s}_{j}<s_{j}^{*}=0, i, j=1,2$ and $i \neq j$.

(vii) If $\beta_{i}=0.5$ and $0.5<\beta_{j} \leq 1, \tilde{s}_{i}=s_{i}^{*}=0,0=s_{j}^{*}<\tilde{s}_{j}, i, j=1,2$ and $i \neq j$. 
When both spillovers are greater than $0.5,0<s_{i}^{*}<\tilde{s}_{i}$, so the usual character of the prisoners' dilemma does not exist, and the joint welfare increases further with the R\&D subsidies being higher than under non-cooperation. When one spillover rate is less than 0.5 but the other is greater than 0.5 , the governments of the two countries should adopt opposite jointly optimal policies; that is, one should apply a tax and the other a subsidy. ${ }^{17}$ When both spillovers are less than 0.5 , the jointly optimal policy of at least one of the governments is an R\&D tax.

\section{Concluding Remarks}

This paper has investigated the non-cooperative and jointly optimal R\&D subsidy policies under the framework of Spencer \& Brander (1983) in the presence of R\&D spillovers. When the two governments choose their policies non-cooperatively, they may tax R\&D when the degree of spillovers is moderate. When they choose their policies cooperatively, the jointly optimal policy depends on the R\&D externality. When spillovers are low, the R\&D performed by one firm reduces the profit of the other firm, so the jointly optimal policy is to tax R\&D in order to internalize the negative externality. On the other hand, when spillovers are high, the R\&D game exhibits a positive externality, so the jointly optimal policy is to subsidize $\mathrm{R} \& \mathrm{D}$.

We find that the result in Spencer \& Brander (1983) is still applicable if the spillover effect is sufficiently small so that $\mathrm{R} \& \mathrm{D}$ activities are strategic substitutes and the R\&D game exhibits a negative externality. However, if R\&D activities are strategic substitutes and the R\&D game exhibits a positive externality, the result of Spencer \& Brander (1983) is reversed: the non-cooperative policy is a tax while the jointly optimal policy is a subsidy. Our results also reveal that the usual result of the prisoners' dilemma in the strategic subsidy game does not hold when the competing variables are strategic complements. Thus, a welfare intervention is preferable over laissez-faire. When R\&D activities are strategic complements and the R\&D game exhibits a positive externality, the jointly optimal R\&D subsidy is greater than the non-cooperative R\&D subsidy, implying that the total welfare will be increased further if the governments provide higher R\&D subsidies for the firms in their countries. However, when R\&D activities are strategic complements and the R\&D game exhibits a negative externality, the total welfare will be increased further if the governments impose R\&D taxes on the firms in their countries that are higher than the non-cooperative taxes.

The case of asymmetric spillovers between firms has also been analyzed. With a linear demand, the jointly optimal policy for the government in each country will differ when one spillover rate is less than 0.5 and the other is greater than

\footnotetext{
${ }^{17}$ Park (2001) and Zhou et al. (2002) also demonstrate the case where countries may choose R\&D policies that are in opposite directions where firms engage in $R \& D$ activities to improve quality and they produce differentiated products due to asymmetric R\&D costs.
} 
0.5. The government of a country with a spillover rate that is less (greater) than 0.5 should tax (subsidize) R\&D.

Under the Agreement of Subsidies and Countervailing Measures (SCM Agreement), members of the World Trade Organization (WTO) may, under certain conditions specified in the Agreement, apply 'non-actionable subsidies' to assist the R\&D activities of firms. However, the provisions concerning non-actionable subsidies of the SCM Agreement expired at the end of 1999, and there has been ongoing discussion about reintroducing them into the Agreement. The results of this paper indicate that the desirability of allowing R\&D subsidies varies with the degree of R\&D spillovers, and hence WTO members should take R\&D spillovers into consideration when negotiating the issue of non-actionable subsidies.

\section{Acknowledgements}

I am grateful to the journal editor, Jaymin Lee, and two anonymous referees for their valuable comments and suggestions. I gratefully acknowledge the financial support of the National Science Council, Taiwan, under grant no. NSC 94-2415H-002-021.

\section{References}

Bagwell, K. \& Staiger, R.W. (1992) The sensitivity of strategic and corrective R\&D policy in battles for monopoly, International Economic Review, 33(4), pp. 795-816.

Bagwell, K. \& Staiger, R.W. (1994) The sensitivity of strategic and corrective R\&D policy in oligopolistic industries, Journal of International Economics, 36(1-2), pp. 133-150.

d'Aspremont, C. \& Jacquemin, A. (1988) Cooperative and noncooperative R\&D in duopoly with spillovers, American Economic Review, 78(5), pp. 1133-1137.

DeCourcy, J. (2005) Cooperative R\&D and strategic trade policy, Canadian Journal of Economics, 38(2), pp. 546-573.

Kamien, M.I., Muller, E. \& Zang, I. (1992) Research joint ventures and R\&D cartels, American Economic Review, 82(5), pp. 1293-1306.

Kang, M. (2006) Trade policy mix: IPR protection and R\&D subsidies, Canadian Journal of Economics, 39(3), pp. 744-757.

Leahy, D. \& Neary, J.P. (1996) International R\&D rivalry and industrial strategy without government commitment, Review of International Economics, 4(3), pp. 322-338.

Miyagiwa, K. \& Ohno, Y. (1997) Strategic R\&D policy and appropriability, Journal of International Economics, 42(1-2), pp. 125-148.

Motta, M. (1996) Research joint ventures in an international economy, Ricerche Economiche, 50(3), pp. $293-315$.

Park, J.-H. (2001) Strategic R\&D policy under vertically differentiated oligopoly, Canadian Journal of Economics, 34(4), pp. 967-987.

Qiu, L.D. \& Tao, Z. (1998) Policy on international R\&D cooperation: subsidy or tax? European Economic Review, 42(9), pp. 1727-1750.

Spencer, B.J. \& Brander, J.A. (1983) International R\&D rivalry and industrial strategy, Review of Economic Studies, 50(4), pp. 707-722.

Suzumura, K. (1992) Cooperative and noncooperative R\&D in an oligopoly with spillovers, American Economic Review, 82(5), pp. 1307-1320.

Zhou, D., Spencer, B.J. \& Vertinsky, I. (2002) Strategic trade policy with endogenous choice of quality and asymmetric costs, Journal of International Economics, 56(1), pp. 205-232. 


\section{Appendix A}

Since $\partial q_{i}^{*} / \partial x_{j}=p^{\prime \prime}\left(q_{i}^{*}-\beta q_{j}^{*}\right) / \Delta_{1}+(1-2 \beta) /\left(p^{\prime \prime} Q^{*}+3 p^{\prime}\right)$, we have

$$
\begin{aligned}
\frac{\partial^{2} q_{i}^{*}}{\partial x_{j} \partial x_{i}}= & \frac{\left[p^{\prime \prime \prime}\left(\frac{\partial Q^{*}}{\partial x_{i}}\right)\left(q_{i}^{*}-\beta q_{j}^{*}\right)+p^{\prime \prime}\left(\frac{\partial q_{i}^{*}}{\partial x_{i}}-\beta \frac{\partial q_{j}^{*}}{\partial x_{i}}\right)\right]}{\Delta_{1}} \\
& -\frac{p^{\prime \prime}\left(q_{i}^{*}-\beta q_{j}^{*}\right)\left[-\frac{(1+\beta)\left(p^{\prime \prime 2} Q^{*}+7 p^{\prime} p^{\prime \prime}+p^{\prime} p^{\prime \prime \prime} Q^{*}\right)}{p^{\prime \prime} Q^{*}+3 p^{\prime}}\right]}{\left(\Delta_{1}\right)^{2}} \\
& -\frac{1-2 \beta}{\left(p^{\prime \prime} Q^{*}+3 p^{\prime}\right)^{2}}\left[-\frac{(1+\beta)\left(4 p^{\prime \prime}+p^{\prime \prime \prime} Q^{*}\right)}{p^{\prime \prime} Q^{*}+3 p^{\prime}}\right]
\end{aligned}
$$

With symmetry and some mathematical manipulation, we obtain

$$
\frac{\partial^{2} q_{i}^{*}}{\partial x_{j} \partial x_{i}}=-\frac{(1+\beta)^{2}\left(p^{\prime \prime \prime} q^{*}+2 p^{\prime \prime}\right)}{\left(p^{\prime \prime} Q^{*}+3 p^{\prime}\right)^{3}}
$$

Substituting $\partial^{2} q_{i}^{*} / \partial x_{j} \partial x_{i}$ into $b_{j i}$ yields equation (3). When $\beta=0, b_{j i}$ in equation (3) becomes

$$
\left.b_{j i}\right|_{\beta=0}=\frac{\left(p^{\prime \prime} q^{*}+p^{\prime}\right)\left(p^{\prime \prime} Q^{*}+4 p^{\prime}\right)\left(p^{\prime \prime} Q^{*}+3 p^{\prime}\right)-\left(p^{\prime}\right)^{2} q^{*}\left(p^{\prime \prime \prime} q^{*}+2 p^{\prime \prime}\right)}{p^{\prime}\left(p^{\prime \prime} Q^{*}+3 p^{\prime}\right)^{3}}
$$

If $p^{\prime \prime \prime} q^{*}+2 p^{\prime \prime} \geq 0,\left.\quad b_{j i}\right|_{\beta=0}<0$. If $p^{\prime \prime \prime} q^{*}+2 p^{\prime \prime}<0$, since $p^{\prime \prime \prime}$ is negligible, $\left.b_{j i}\right|_{\beta=0}<0$. When $\beta=1, b_{j i}$ in equation (3) becomes

$$
\begin{aligned}
\left.b_{j i}\right|_{\beta=1} & =\frac{-2\left(p^{\prime}\right)^{2}\left(p^{\prime \prime} Q^{*}+3 p^{\prime}\right)-4\left(p^{\prime}\right)^{2} q^{*}\left(p^{\prime \prime \prime} q^{*}+2 p^{\prime \prime}\right)}{p^{\prime}\left(p^{\prime \prime} Q^{*}+3 p^{\prime}\right)^{3}} \\
& =-\frac{2 p^{\prime}\left[3\left(p^{\prime \prime} Q^{*}+p^{\prime}\right)+p^{\prime \prime \prime} q^{*} Q^{*}\right]}{\left(p^{\prime \prime} Q^{*}+3 p^{\prime}\right)^{3}}>0
\end{aligned}
$$

for $p^{\prime \prime \prime}$ being negligible.

Differentiating equation (3) with respect to $\beta$ yields

$$
\frac{\partial b_{j i}}{\partial \beta}=\left[\frac{-\left(p^{\prime \prime} q^{*}+2 p^{\prime}\right)}{p^{\prime}\left(p^{\prime \prime} Q^{*}+3 p^{\prime}\right)}\right]\left[\frac{(1-\beta)\left(p^{\prime \prime} Q^{*}+2 p^{\prime}\right)+2 p^{\prime}}{p^{\prime \prime} Q^{*}+3 p^{\prime}}\right]
$$




$$
\begin{aligned}
& +\left[\frac{(1-\beta)\left(p^{\prime \prime} q^{*}+2 p^{\prime}\right)-p^{\prime}}{p^{\prime}\left(p^{\prime \prime} Q^{*}+3 p^{\prime}\right)}\right]\left(-\frac{p^{\prime \prime} Q^{*}+2 p^{\prime}}{p^{\prime \prime} Q^{*}+3 p^{\prime}}\right) \\
& -\left[\frac{2 p^{\prime} q^{*}(1+\beta)\left(p^{\prime \prime \prime} q^{*}+2 p^{\prime \prime}\right)}{\left(p^{\prime \prime} Q^{*}+3 p^{\prime}\right)^{3}}\right] \\
& =\frac{-\left(p^{\prime \prime} Q^{*}+3 p^{\prime}\right)\left[2(1-\beta)\left(p^{\prime \prime} q^{*}+2 p^{\prime}\right)\left(p^{\prime \prime} Q^{*}+2 p^{\prime}\right)+2\left(p^{\prime}\right)^{2}\right]}{p^{\prime}\left(p^{\prime \prime} Q^{*}+3 p^{\prime}\right)^{3}} \\
& >\frac{-2\left(p^{\prime}\right)^{2}\left(p^{\prime \prime} Q^{*}+3 p^{\prime}\right)-(1+\beta)\left(p^{\prime}\right)^{2} Q^{*}\left(p^{\prime \prime \prime} q^{*}+2 p^{\prime \prime}\right)}{p^{\prime}\left(p^{\prime \prime} Q^{*}+3 p^{\prime}\right)^{3}}
\end{aligned}
$$

$$
\begin{aligned}
& \text { If } p^{\prime \prime \prime} q^{*}+2 p^{\prime \prime} \leq 0, \partial b_{j i} / \partial \beta>0 \text {. If } p^{\prime \prime \prime} q^{*}+2 p^{\prime \prime}>0, \\
& \qquad \begin{aligned}
-2\left(p^{\prime}\right)^{2}\left(p^{\prime \prime} Q^{*}+3 p^{\prime}\right)-(1+\beta)\left(p^{\prime}\right)^{2} Q^{*}\left(p^{\prime \prime \prime} q^{*}+2 p^{\prime \prime}\right) \\
>-2\left(p^{\prime}\right)^{2}\left(p^{\prime \prime} Q^{*}+3 p^{\prime}\right)-2\left(p^{\prime}\right)^{2} Q^{*}\left(p^{\prime \prime \prime} q^{*}+2 p^{\prime \prime}\right) \\
=-2\left(p^{\prime}\right)^{2}\left[3\left(p^{\prime \prime} Q^{*}+p^{\prime}\right)+p^{\prime \prime \prime} q^{*} Q^{*}\right] \\
>0
\end{aligned}
\end{aligned}
$$

for $p^{\prime \prime \prime}$ being negligible, and thus $\partial b_{j i} / \partial \beta>0$. Therefore, we have $\left.b_{j i}\right|_{\beta=0}<0$, $\left.b_{j i}\right|_{\beta=1}>0$, and $\partial b_{j i} / \partial \beta>0$.

\section{Appendix B}

To compare $\beta_{e}$ with $\beta_{s}$, substitute $\beta_{e}$ into equation (3). If $\left.b_{j i}\right|_{\beta=\beta_{e}}<(>) 0$, then $\beta_{e}<(>) \beta_{s}$. If $\left.b_{j i}\right|_{\beta=\beta_{e}}=0$, then $\beta_{e}=\beta_{s}$. We have

$$
\begin{aligned}
\left.b_{j i}\right|_{\beta=\beta_{e}}= & {\left[\frac{\left(1-\beta_{e}\right)\left(p^{\prime \prime} q^{*}+2 p^{\prime}\right)-p^{\prime}}{p^{\prime}\left(p^{\prime \prime} Q^{*}+3 p^{\prime}\right)}\right]\left[\frac{\left(1-\beta_{e}\right)\left(p^{\prime \prime} Q^{*}+2 p^{\prime}\right)+2 p^{\prime}}{p^{\prime \prime} Q^{*}+3 p^{\prime}}\right] } \\
& -\left[\frac{p^{\prime} q^{*}\left(1+\beta_{e}\right)^{2}\left(p^{\prime \prime \prime} q^{*}+2 p^{\prime \prime}\right)}{\left(p^{\prime \prime} Q^{*}+3 p^{\prime}\right)^{3}}\right] \\
= & {\left[\frac{p^{\prime \prime} q^{*}}{p^{\prime}\left(3 p^{\prime \prime} q^{*}+4 p^{\prime}\right)}\right]\left(\frac{p^{\prime \prime} Q^{*}+4 p^{\prime}}{3 p^{\prime \prime} q^{*}+4 p^{\prime}}\right) } \\
& -\left[\frac{8 p^{\prime} p^{\prime \prime} q^{*}+4 p^{\prime} p^{\prime \prime \prime} q^{* 2}}{\left(p^{\prime \prime} Q^{*}+3 p^{\prime}\right)\left(3 p^{\prime \prime} q^{*}+4 p^{\prime}\right)^{2}}\right]
\end{aligned}
$$




$$
\begin{aligned}
& =\frac{q^{*}\left[p^{\prime \prime}\left(p^{\prime \prime} Q^{*}+4 p^{\prime}\right)\left(p^{\prime \prime} Q^{*}+3 p^{\prime}\right)-8\left(p^{\prime}\right)^{2} p^{\prime \prime}-4\left(p^{\prime}\right)^{2} p^{\prime \prime \prime} q^{*}\right]}{p^{\prime}\left(p^{\prime \prime} Q^{*}+3 p^{\prime}\right)\left(3 p^{\prime \prime} q^{*}+4 p^{\prime}\right)^{2}} \\
& =\frac{q^{*}\left\{p^{\prime \prime}\left[\left(p^{\prime \prime} Q^{*}\right)^{2}+7 p^{\prime} p^{\prime \prime} Q^{*}+4\left(p^{\prime}\right)^{2}\right]-4\left(p^{\prime}\right)^{2} p^{\prime \prime \prime} q^{*}\right\}}{p^{\prime}\left(p^{\prime \prime} Q^{*}+3 p^{\prime}\right)\left(3 p^{\prime \prime} q^{*}+4 p^{\prime}\right)^{2}}
\end{aligned}
$$

The sign of $\left.b_{j i}\right|_{\beta=\beta_{e}}$ is indeterminate. When $p^{\prime \prime}<0$ (concave demand) and $p^{\prime \prime \prime} \geq 0$, $\left.b_{j i}\right|_{\beta=\beta_{e}}<0$, so $\beta_{e}<\beta_{s}$. When $p^{\prime \prime}=p^{\prime \prime \prime}=0$ (linear demand), $\left.b_{j i}\right|_{\beta=\beta_{e}}=0$, so $\beta_{e}=\beta_{s}$. Moreover, it is obvious from equation (7) that $\beta_{e}=0.5$ when $p^{\prime \prime}=0$.

\section{Appendix C}

Suppose that $p=a-b Q^{2}$. Thus, $p^{\prime}=-2 b Q, p^{\prime \prime}=-2 b$, and $p^{\prime \prime \prime}=0$. The second-order condition $a_{i i}=p^{\prime \prime} q_{i}+2 p^{\prime}=-2 b q_{i}-4 b Q<0$ and the stability condition $\Delta_{1}=p^{\prime} p^{\prime \prime} Q+3\left(p^{\prime}\right)^{2}=16 b^{2} Q^{2}>0$ are satisfied. With symmetry, $q_{i}^{*}=q_{j}^{*}=q^{*}=Q^{*} / 2$, and from equation (7) we have

$$
\beta_{e}=\frac{p^{\prime \prime} q^{*}+2 p^{\prime}}{3 p^{\prime \prime} q^{*}+4 p^{\prime}}=\frac{-2 b q^{*}-4 b Q^{*}}{-6 b q^{*}-8 b Q^{*}}=\frac{-5 b Q^{*}}{-11 b Q^{*}}=\frac{5}{11}
$$

To derive $\beta_{s}$, substitute $p^{\prime}=-2 b Q, p^{\prime \prime}=-2 b$, and $p^{\prime \prime \prime}=0$ into equation ( 3 ) and let it equal zero. We can derive $b_{j i}=\left(-29 \beta^{2}+70 \beta-29\right) / 128 b Q^{*}=0$. Thus, $\beta_{s}=0.5312$.

This example confirms Lemma 1 : when $p^{\prime \prime}=-2 b<0$ and $p^{\prime \prime \prime}=0, \beta_{e}<\beta_{s}$.

\section{Appendix D}

Suppose that $p=a-b \ln Q$. Thus, $p^{\prime}=-b / Q, p^{\prime \prime}=b / Q^{2}$, and $p^{\prime \prime \prime}=-2 b / Q^{3}$. The second-order condition $a_{i i}=p^{\prime \prime} q_{i}+2 p^{\prime}=\left(b / Q^{2}\right) q_{i}-(2 b / Q)<0$ and the stability condition $\Delta_{1}=p^{\prime} p^{\prime \prime} Q+3\left(p^{\prime}\right)^{2}=2 b^{2} / Q^{2}>0$ are satisfied. With symmetry, $q_{i}^{*}=q_{j}^{*}=q^{*}=Q^{*} / 2$, and from equation (7) we have

$$
\beta_{e}=\frac{p^{\prime \prime} q^{*}+2 p^{\prime}}{3 p^{\prime \prime} q^{*}+4 p^{\prime}}=\frac{\frac{b}{2 Q^{*}}-\frac{2 b}{Q^{*}}}{\frac{3 b}{2 Q^{*}}-\frac{4 b}{Q^{*}}}=\frac{-\frac{3 b}{2 Q^{*}}}{-\frac{5 b}{2 Q^{*}}}=\frac{3}{5}=0.6
$$

To derive $\beta_{s}$, substitute $p^{\prime}=-b / Q, p^{\prime \prime}=b / Q^{2}$, and $p^{\prime \prime \prime}=-2 b / Q^{3}$ into equation (3) and let it equal zero. We can derive $b_{j i}=\left[\left(-7 \beta^{2}+18 \beta-7\right) Q^{*}\right] /(16 b)=0$. Thus, $\beta_{s}=0.4776$.

\section{Appendix E}

Under the assumption that the demand is linear with $p=a-b Q$ and $c_{1}=c_{2}=$ $c$, we can derive the equilibrium outputs in the third stage and the equilibrium 
R\&D levels in the second stage as follows:

$$
\begin{aligned}
q_{i}^{*} & =\frac{1}{3 b}\left[a-c+\left(2-\beta_{i}\right) x_{i}+\left(2 \beta_{j}-1\right) x_{j}\right], \\
x_{i}^{*} & =\frac{2(a-c)\left(2-\beta_{i}\right)\left[3 b \gamma\left(1-s_{j}\right)-2\left(1-\beta_{j}\right)\left(2-\beta_{j}\right)\right]}{\Delta}
\end{aligned}
$$

where $\Delta=27 b^{2} \gamma^{2}\left(1-s_{1}\right)\left(1-s_{2}\right)-6 b \gamma\left(1-s_{1}\right)\left(2-\beta_{2}\right)^{2}-6 b \gamma\left(1-s_{2}\right)(2-$ $\left.\beta_{1}\right)^{2}+4\left(2-\beta_{1}\right)\left(2-\beta_{2}\right)\left(1-\beta_{1} \beta_{2}\right)>0$ by the stability condition. The secondorder conditions for the profit maximization problem in the second stage are $9 b \gamma\left(1-s_{i}\right)-2\left(2-\beta_{i}\right)^{2}>0, i=1,2$. Moreover, we assume that $3 b \gamma\left(1-s_{i}\right)-$ $2\left(1-\beta_{i}\right)\left(2-\beta_{i}\right)>0$ for a non-negative $x_{i}^{*}, i=1,2$.

It can be shown that $\partial x_{i}^{*} / \partial s_{i}=3 b \gamma x_{i}^{*}\left[9 b \gamma\left(1-s_{j}\right)-2\left(2-\beta_{j}\right)^{2}\right] / \Delta>0$ and $\partial x_{j}^{*} / \partial s_{i}=6 b \gamma x_{i}^{*}\left(2 \beta_{i}-1\right)\left(2-\beta_{j}\right) / \Delta$, whose sign depends on $\beta_{i}$. Thus, we have

$$
\begin{aligned}
\left.\frac{\partial\left(W_{i}+W_{j}\right)}{\partial s_{i}}\right|_{s_{i}=s_{j}=0}= & q_{j}^{*}\left(\beta_{i}+p^{\prime} \frac{\partial q_{i}^{*}}{\partial x_{i}}\right)\left(\frac{\partial x_{i}^{*}}{\partial s_{i}}\right)+q_{i}^{*}\left(\beta_{j}+p^{\prime} \frac{\partial q_{j}^{*}}{\partial x_{j}}\right)\left(\frac{\partial x_{j}^{*}}{\partial s_{i}}\right) \\
= & \frac{2 b \gamma q_{j}^{*} x_{i}^{*}\left(2 \beta_{i}-1\right)\left[9 b \gamma-2\left(2-\beta_{j}\right)^{2}\right]}{\Delta} \\
& +\frac{4 b \gamma q_{i}^{*} x_{i}^{*}\left(2 \beta_{i}-1\right)\left(2 \beta_{j}-1\right)\left(2-\beta_{j}\right)}{\Delta} \\
= & \frac{2 b \gamma x_{i}^{*}\left(2 \beta_{i}-1\right)}{\Delta}\left\{q_{j}^{*}\left[9 b \gamma-2\left(2-\beta_{j}\right)^{2}\right]\right. \\
& \left.+2 q_{i}^{*}\left(2 \beta_{j}-1\right)\left(2-\beta_{j}\right)\right\}
\end{aligned}
$$

When $\beta_{j} \leq \beta_{i}$, it can be shown that $x_{i}^{*} \leq x_{j}^{*}$ and $q_{i}^{*} \leq q_{j}^{*}$, and we have

$$
\begin{aligned}
q_{j}^{*} & {\left[9 b \gamma-2\left(2-\beta_{j}\right)^{2}\right]+2 q_{i}^{*}\left(2 \beta_{j}-1\right)\left(2-\beta_{j}\right) } \\
& \geq q_{i}^{*}\left[9 b \gamma-2\left(2-\beta_{j}\right)^{2}+2\left(2 \beta_{j}-1\right)\left(2-\beta_{j}\right)\right] \\
& =3 q_{i}^{*}\left[3 b \gamma-2\left(1-\beta_{j}\right)\left(2-\beta_{j}\right)\right] \\
& >0
\end{aligned}
$$

Thus, when $\beta_{j}<0.5<\beta_{i}, \partial\left(W_{i}+W_{j}\right) /\left.\partial s_{i}\right|_{s_{i}=s_{j}=0}>0$, and when $\beta_{j} \leq \beta_{i}<0.5$, $\partial\left(W_{i}+W_{j}\right) /\left.\partial s_{i}\right|_{s_{i}=s_{j}=0}<0$.

However, when $\beta_{i}<\beta_{j}<0.5, q_{j}^{*}<q_{i}^{*}$ and the sign of $q_{j}^{*}\left[9 b \gamma-2\left(2-\beta_{j}\right)^{2}\right]+$ $2 q_{i}^{*}\left(2 \beta_{j}-1\right)\left(2-\beta_{j}\right)$ is ambiguous because it is possible that the (negative) second term is greater than the (positive) first term. If $b \gamma$ is sufficiently large so that the first term is greater than the second term, then $q_{j}^{*}\left[9 b \gamma-2\left(2-\beta_{j}\right)^{2}\right]+2 q_{i}^{*}\left(2 \beta_{j}-\right.$ 1) $\left(2-\beta_{j}\right)>0$ and $\partial\left(W_{i}+W_{j}\right) /\left.\partial s_{i}\right|_{s_{i}=s_{j}=0}<0$. 
Copyright of International Economic Journal is the property of Routledge and its content may not be copied or emailed to multiple sites or posted to a listserv without the copyright holder's express written permission. However, users may print, download, or email articles for individual use. 